\title{
La figura femenina en el cartel político y social en Cataluña (1931-1939)
}

\author{
Alfonso GonZÁLEZ QueSADA \\ Universitat Autònoma de Barcelona \\ Alfons.Gonzalez@uab.cat \\ Patrícia Lázaro Pernias \\ Universitat Autònoma de Barcelona \\ Patricia.Lazaro@uab.cat
}

\section{Resumen}

Este artículo estudia la representación de la figura femenina en el cartel de contenido político y social, editado en Cataluña entre 1931 y 1939. Para ello se ha elaborado un censo exhaustivo con 172 obras y se ha realizado un análisis de contenido de su discurso visual. Los resultados obtenidos han permitido distinguir entre un uso simbólico de la figura femenina y la representación de lo que se ha denominado 'mujer real'. El estudio de esta representación durante la Guerra Civil ha identificado tres arquetipos: 'mujer-heroína', 'mujer-víctima' y 'mujer-trampa'.

Palabras clave: Mujeres, carteles, propaganda política, Segunda República, Guerra Civil, Cataluña.

\section{The female figure on the political and social poster in Catalonia (1931-1939)}

\begin{abstract}
This article examines the representation of the female figure in the political and social posters published in Catalonia between 1931 and 1939. A comprehensive census with 172 works has been developed and a content analysis of visual discourse was performed. The results allowed distinguishing between a symbolic use of the female figure and the representation of what has been called the 'real woman'. During the study of this representation during the Civil War three archetypes were identified: 'heroine-woman', 'victim-woman' and 'trap-woman'.
\end{abstract}

Key Words: women, posters, political propaganda, Spanish Second Republic, Spanish Civil War, Catalonia

\section{Referencia normalizada:}

González Quesada, A. y Lázaro Pernias, P. (2013) La figura femenina en el cartel político y social en Cataluña (1931-1939). Historia y Comunicación Social. Vol. 18. Nºspecial Diciembre. Págs. 173-186.

Sumario: 1. Introducción. 2. Objetivo y metodología. 3. Desarrollo. 3.1 Características generales de los carteles censados. 3.2. Los carteles con niñas. 3.3. Uso simbólico de la figura femenina. 3.4. Representación de la mujer real. 3.4.1. La mujer en el periodo 1931-36. 3.4.2. La mujer en la Guerra Civil. 4. Conclusiones. 5. Bibliografía. 


\section{Introducción}

El horizonte de emancipación inaugurado por la legalidad republicana generó un profundo debate social interrumpido por el final de la Guerra Civil. Durante aquella turbulenta y trágica década, el cartel en España superó el ámbito de la publicidad comercial para convertirse en herramienta de movilización social y política, contribuyendo al modelado de opiniones, valores y conductas.

Los primeros carteles que saludaron a la Segunda República se sirvieron de la figura femenina. Algunos retomaron la alegoría de la 'Niña Bonita' de 1873, eco a su vez de la tradición francesa revolucionaria y republicana. Pero la presencia de la mujer en el discurso propagandístico no se limitó a la representación simbólica del régimen instituido en abril de 1931. Reflejó de manera progresiva, aunque no mimética, el debate en torno a las libertades que la nueva legalidad establecía para la mujer. La igualdad entre sexos en múltiples ámbitos, el sufragio universal, la escuela mixta o el divorcio por mutuo acuerdo significaron para las mujeres la conquista de la ciudadanía social y política. La amenaza que la guerra supuso para el mantenimiento de aquellos logros empujó a muchas mujeres a defenderlos a través de actitudes y tareas hasta entonces reservadas a los hombres. La propaganda supo hacerse eco de aquel compromiso.

Pese a su indudable valor como testimonio histórico, cualquier aproximación al estudio del cartel no puede obviar que se trata de un producto comunicativo con finalidad persuasiva, y que su vocación última no es la de narrar fielmente la historia. Si se asume que no puede establecerse una correlación directa entre imagen y acontecer, también es ineludible aceptar que el cartel entre 1931 y 1939 traduce una óptica muy particular en la construcción del papel asignado a la mujer. Hay un elemento insoslayable: la práctica totalidad de diseñadores de la época eran hombres, así como quienes controlaban los órganos de propaganda de las instituciones editoras, lo que determinó que la representación de la figura femenina se hiciera desde una mirada absolutamente masculina.

Esta contribución parte de la idea del cartel como un elemento más, a través del cual comprender cómo se construyó la representación social de la mujer en la Cataluña republicana y no como un testimonio fidedigno de los procesos que conformaron aquella realidad. Por otro lado, se ha optado tanto por la exhaustividad en la búsqueda y localización de carteles, como por el estudio del discurso visual a partir de unidades de análisis cuantificables para alejarse de interpretaciones sustentadas en muestras excesivamente parciales.

\section{Objetivo y metodología}

Este artículo se basa en los resultados de una investigación financiada por el Centre d'Història Contemporània de Catalunya, dependiente del Departament de Presidèn- 
cia de la Generalitat de Catalunya. Su objetivo era describir la evolución de la representación de la figura femenina en el cartel de carácter político y social, editado en Cataluña en el periodo que va desde la proclamación de la Segunda República hasta la conclusión de la Guerra Civil.

Una aproximación integral al cartel exigiría la contribución de múltiples disciplinas. Porque, tal y como propone la entipología, el estudio de cualquier producto gráfico supone su clasificación, descripción y análisis a partir de diversas perspectivas y enfoques metodológicos: inductivo, deductivo, histórico, funcional, técnico y estético (Tena, 2005: 157-158). Esta investigación ha priorizado la perspectiva histórica, que "estudia la evolución en el tiempo del producto gráfico en un determinado contexto histórico" (Tena, Ibid.); la estética, que "analiza la configuración de los elementos visuales del impreso" (Tena, Ibid.); y en último término, aunque en menor medida, la funcional, dedicada a "observar el uso que los receptores y la sociedad hacen de los productos gráficos" (Tena, Ibid.).

Atendiendo a estos enfoques, en el desarrollo de la investigación se plantearon distintas etapas metodológicas basadas en el análisis de contenido iconográfico: una primera, orientada al estudio descriptivo de los carteles; seguida del análisis de las distribuciones de frecuencia y de contingencias de las informaciones obtenidas. Por último, los resultados más relevantes se confrontaron con el relato historiográfico.

Para el estudio descriptivo se elaboró un censo con los carteles que se ajustaban a los criterios de selección siguientes: obras de temática política y social; editadas en Cataluña, independientemente de su lengua; con figuras femeninas completas o partes de su anatomía reconocibles. Se excluyeron los carteles que, pese a referirse a mujeres, no contenían figuras femeninas. En la búsqueda de las obras se consultó una amplia gama de recursos bibliográficos y archivísticos al no existir una fuente documental exhaustiva sobre la producción de carteles para la época que cubre el estudio. Posteriormente se confeccionó una ficha para cada cartel, que recogió tres tipos de información: datos registrales (autoría, entidad editora, año, temática, etc.); información textual e información iconográfica. En este último apartado se describieron los elementos compositivos del cartel (número y dimensiones de las figuras femeninas, su ubicación en el espacio gráfico, etc.), así como el tratamiento de los contenidos (acciones realizadas, espacios en los que éstas se desarrollan, indumentaria de las mujeres, presencia de otras figuras humanas, etc.). Algunas de las unidades de análisis se cumplimentaron mediante una lista cerrada de términos para garantizar el tratamiento uniforme de la información.

La explotación de datos combinó el análisis de frecuencias y el de contingencias. El primero permitió determinar el perfil general de los carteles, tanto a partir de su distribución numérica de acuerdo a distintos criterios (periodo de estudio, editores, temática, destinatarios, etc.), como mediante la frecuencia de aparición de los aspectos iconográficos analizados (acciones descritas, indumentaria, figuras humanas que acompañan a la mujer, etc.). Estos resultados han ayudado a objetivar las principales tendencias en el tratamiento de la figura femenina y su evolución en el tiempo. Por su 
parte, el análisis de contingencias, al proporcionar datos sobre relaciones entre dos o más variables (por ejemplo, entre las acciones y los espacios donde se desarrollan), ha contribuido a profundizar en la comprensión de la evolución de las tendencias apuntadas con el estudio de frecuencias.

El análisis de la representación de la mujer no debería desvincularse del conocimiento del proceso histórico que dio lugar a esa representación. Por esa razón, en la última etapa, los resultados más relevantes del análisis de contenido se contrastaron con el relato que ofrece la historiografía. Para ello se consultó bibliografía sobre la historia social de la mujer en el periodo republicano.

\section{Desarrollo}

\subsection{Características generales de los carteles censados}

Se censaron 172 carteles; 45 correspondientes al periodo anterior a la guerra y 127 publicados durante el conflicto. Con el objetivo de comparar y evaluar el número de obras de cada periodo, y ante la ausencia de datos concretos sobre su producción, se tomó como referencia la fuente más exhaustiva: la antología de Carulla (2007), que recoge 74 y 370 obras para cada etapa, respectivamente. En la primera hay 20 carteles con imágenes de mujeres, un $27 \%$ del total, mientras que en la segunda, 94, equivalente al $25^{\prime} 4 \%$. Si se estiman estas cifras en términos relativos, cabe destacar un dato significativo: el porcentaje de obras en las que aparecen figuras femeninas es similar para ambos periodos. Se desprende que, a pesar de que durante la guerra hubo una intensa movilización de la comunicación gráfica, ésta no comportó mayor visibilidad de la figura femenina como recurso visual.

Cerca de las dos terceras partes de los carteles aparecidos entre abril de 1931 y abril de 1939 fueron editados por partidos políticos, sindicatos o entidades de gobierno. El perfil de los partidos varía según la etapa analizada: en la primera destaca su pluralidad ideológica, coherente con las convocatorias electorales; durante el conflicto, los partidos y sindicatos que mayor uso hicieron de la figura femenina fueron socialistas, anarquistas y comunistas.

El análisis temático de los carteles muestra el perfil de la agenda propagandística de cada periodo. Para la etapa 1931-36 se han distinguido 16 temas. Por su frecuencia de aparición destacan los carteles sobre: 'propaganda electoral', 'régimen republicano', 'enseñanza y formación', 'infancia', y 'ayuda y solidaridad'. A lo largo del conflicto el número de temas se duplicó (37). La mayoría se focalizó en asuntos indesligables de la lógica discursiva de la propaganda bélica: 'ayuda y solidaridad', 'sanidad militar' y 'combatientes', a los que hay que añadir temas tratados en la etapa precedente. 


\subsection{Los carteles con niñas}

Se ha distinguido entre los carteles con imágenes de mujeres adultas y los que incluyen niñas; de éstos últimos es significativo su número: 16 de los 45 de la República y 44 de los 127 de la Guerra Civil. La temática de las composiciones de la primera etapa se centra en tres ámbitos: 'propaganda electoral', 'enseñanza' y 'ayuda y solidaridad' hacia los menores. Es característico de estos carteles que las niñas no aparezcan solas, sino acompañadas mayoritariamente por niños. Tampoco se recurre a la figura femenina infantil para ilustrar la estructura familiar. Esos casos se resuelven con el triángulo padre-madre-niño. La guerra amplía la significación de la imagen de niñas y jóvenes como recurso visual, al representar el componente más vulnerable de la estructura social y familiar. A su vez, los binomios niña-mujer y niñas-ancianos, no sólo se hacen eco de los cambios en la estructura familiar a causa de la guerra, sino que señala a las víctimas más débiles del conflicto. De los perfiles temáticos apuntados, de la presencia habitual de niños, y de las estrategias discursivas empleadas se desprende que el uso de figuras de niñas no fue un recurso para hablar de su género, sino para referirse a la infancia.

Los apartados siguientes se centrarán en el estudio de los 150 carteles con figuras femeninas adultas, 37 editados en la etapa 1931-1936 y 113 entre 1936-1939.

\subsection{Uso simbólico de la figura femenina}

La iconografía republicana recoge la tradición iniciada en 1873 de utilizar como imagen del nuevo régimen la figura de una matrona. No es el único uso alegórico que el cartel reserva a la figura femenina a partir de 1931. También personifica entidades territoriales y conceptos como la miseria o la belleza artística. En total, cerca de la mitad $(46 \%)$ de la producción anterior a la guerra emplea de manera simbólica la figura de la mujer. Esta cifra contrasta con la disminución drástica del periodo 36-39, en el que el uso simbólico sólo aparece en el 10\% de obras; signo evidente de un cambio profundo del protagonismo que adquieren las mujeres durante la contienda.

Como mejor se identifica la dimensión simbólica de la figura femenina es a través de su indumentaria. En la etapa previa a la guerra se usan, de forma aislada o combinada, elementos como la túnica, y con menor frecuencia, la bandera, el gorro frigio o la corona mural. La desnudez también es un atributo alegórico. Sin embargo, durante la guerra la túnica dejará paso al traje tradicional como atuendo más recurrente para revestir de simbolismo la figura femenina.

La temática de las composiciones con usos simbólicos se concentra en dos: la propaganda electoral, donde la figura femenina actúa como alegoría de ámbitos territoriales (Cataluña o la ciudad de Barcelona); y la celebración del régimen republicano (imagen 1). En relación a esta temática, es interesante destacar que en la etapa 31-36 hay un equilibrio entre el número de representaciones de la República y Cataluña, mientras que durante la guerra las representaciones de la última doblan a 
las de la primera, porque, en pleno conflicto, está implícita en la defensa de Cataluña la defensa de la legalidad y los valores republicanos.

Imagen 1: Cartel de J. Cuchy (1931).

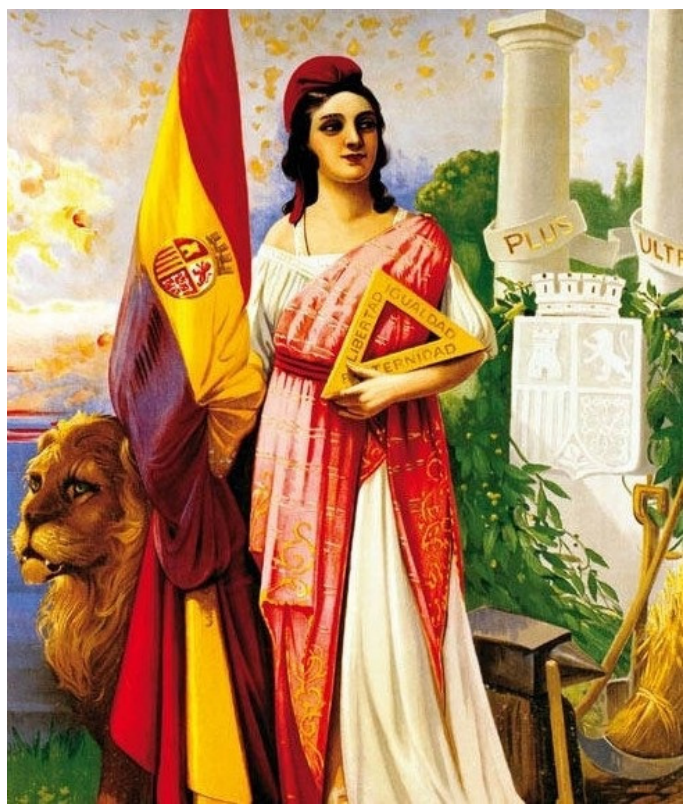

Fuente: Col·lecció Fornas (2006).

\subsection{Representación de la mujer real}

La imagen de la mujer en los carteles es siempre una representación de carácter simbólico; una convención icónica con intención comunicativa. Pero el simbolismo es de índole bien distinta si se muestra la figura de la mujer con un significado arbitrario, lo que se ha descrito anteriormente como "uso simbólico", o con un sentido figurativo, basado en la semejanza entre la representación y aquello que representa. En este caso se hablará de "mujer real".

\subsubsection{La mujer en el periodo 1931-36}

El censo incluye 21 obras con imágenes de mujeres reales. Para caracterizar este conjunto se presentan y relacionan las cuatro unidades de análisis más fértiles: temas, acciones desarrolladas, dimensiones de la figura femenina y presencia de otras figuras humanas.

Del estudio de frecuencias de las temáticas se observa que una tercera parte de los carteles está vinculada con la propaganda electoral (imagen 2). Los dos tercios restantes se reparten equilibradamente entre las obras que proyectan una visión tradicional de la mujer ('infancia', 'ayuda y solidaridad', 'cultura popular'), y las que la 
muestran ocupando los nuevos espacios que la legislación republicana le ha proporcionado ('enseñanza', 'mujer', 'trabajo').

Imagen 2: Gráfica "Mujer real” y temas (periodo 31-36).

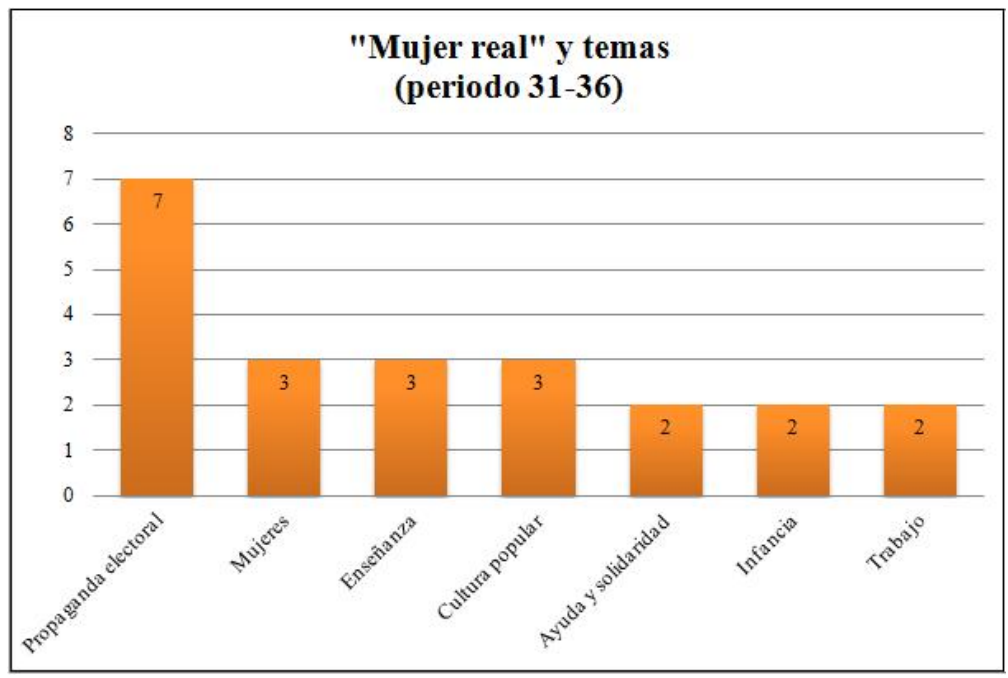

Fuente: elaboración propia.

Las mujeres ejercieron el derecho al voto a partir de 1933. En Cataluña, su participación fue siempre diez puntos inferior a la masculina (Vilanova, 1999: 108). A pesar de que el tema más recurrente fuera la propaganda electoral, la retórica visual dedicó a la figura femenina un papel secundario. No hubo estrategias discursivas que la singularizasen como sujeto político. Solo un cartel se dirige exclusivamente a ella. En el resto, aparece acompañada por figuras masculinas, o integrada en la estructura familiar, porque, como apunta Vilanova (1986: 165), en muchas ocasiones la opción del voto constituyó una decisión familiar.

Tampoco es mayor el protagonismo que el cartel reserva a la mujer en el ámbito laboral. Si se atiende a los temas o a las acciones, sólo cuatro composiciones la relacionan con el trabajo, lo que supone el 19\% de las obras. No hay que olvidar la baja tasa de actividad femenina durante la República, que en 1931 apenas superaba el 14\% (Domingo, 2004: 94).

Las acciones que llevan a cabo figuras femeninas se identifican en 18 carteles. De esas acciones se desprende un equilibrio entre las desarrolladas en el ámbito privado y las que lo hacen en espacios públicos. Las primeras (amamantar, abrazar y besar niños o llorar) son propias de la esfera privada, y conforman la gestualidad doméstica que intensifica la idea tradicional de feminidad. Las segundas hablan del papel activo de la mujer, de conquista de terrenos como el laboral, educativo o deportivo. Aguado (2011: 25) asegura que "la imagen de la modernidad republicana se traduce simbó- 
licamente en el caso de las mujeres, en la salida del hogar, del recinto privado, para pasearse por las calles (...)".

Finalmente, el estudio de la dimensión de las imágenes de mujeres y el de la presencia de otras figuras en las composiciones confirman la dicotomía entre las esferas doméstica y pública. Si bien las cifras no apuntan grandes diferencias, se tiende al uso de planos cortos para acentuar la expresividad y la emoción en aquellas obras que destacan el estereotipo de la feminidad. Los planos abiertos se reservan para reforzar la presencia pública mostrando con claridad la acción realizada e integrándola en un contexto reconocible. En cuanto a la incorporación de otras figuras humanas, existen tres tratamientos compositivos. El primero prioriza la individualidad de la mujer al presentarla sola. Se trata siempre de una mujer anónima. En el segundo aparece acompañada de otras mujeres, pertenecientes a colectivos identificables como trabajadoras, estudiantes y deportistas. En el tercero, comparte el espacio con el hombre, tanto para representar estructuras familiares tradicionales como para reflejar la igualdad entre géneros.

\subsubsection{La mujer en la Guerra Civil}

El número de carteles que muestran a la 'mujer real' durante la Guerra Civil (107) se quintuplica en relación con la etapa precedente. La causa del aumento en la producción fue la propia dinámica del conflicto, que impuso una nueva agenda en la propaganda y condujo al tratamiento de un mayor número de temas (imagen 3). Este enriquecimiento temático ('sanidad miliar', 'combatientes', 'revolución', 'refugiados', 'enfermedades venéreas') se concentró en dos ejes narrativos: el que sitúa a la mujer en el frente y el que destaca la feminización de la retaguardia.

Imagen 3: Gráfica "Mujer real” y temas (periodo 36-39)

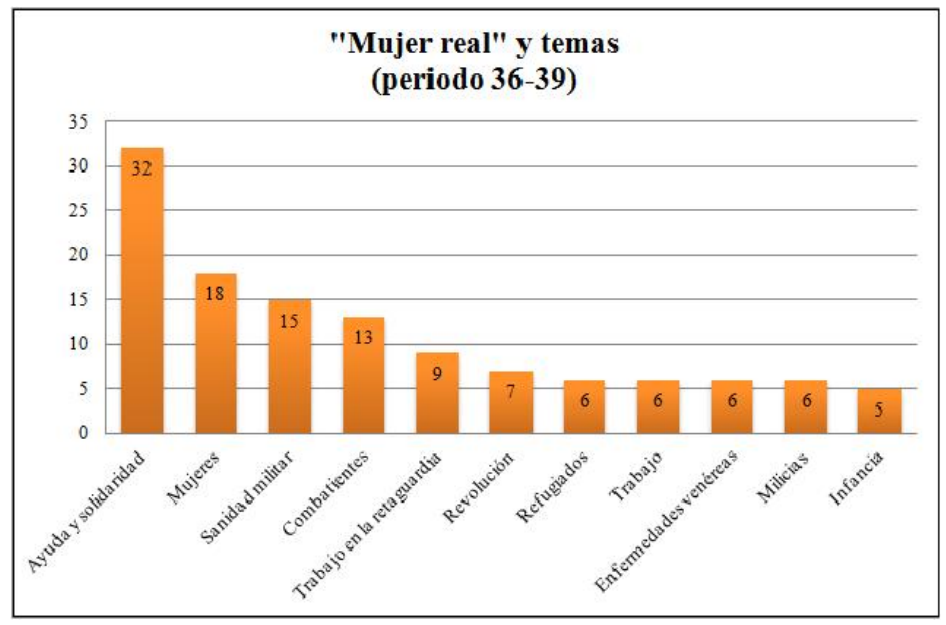

Fuente: elaboración propia. 
Ambos ejes permiten distinguir tres arquetipos de figura femenina. El mayoritario traduce los valores de la 'mujer-heroína': comprometida con el esfuerzo bélico; dispuesta a colaborar en el proceso productivo (imagen 4); abnegada, solidaria y generosa en el servicio a la colectividad o en el auxilio a combatientes, niños y refugiados. Esta dimensión asistencial que recoge la propaganda seguía, como afirma Branciforte (2009: 32) "aprovechándose de la difusión de la antigua idea de la doble moral que atribuía a las mujeres sentimientos (dulzura, gracia, timidez) y virtudes sensitivas, distintas a las de los hombres". El segundo corresponde a la "mujer-víctima', aquella a quien la guerra ha convertido en vulnerable y desarraigada (imagen $5)$.

Imagen 4 (izquierda): Cartel de R. Tona. Imagen 5 (derecha): Cartel editado por el Comité d'Ajut Permanent a Madrid, 1937.

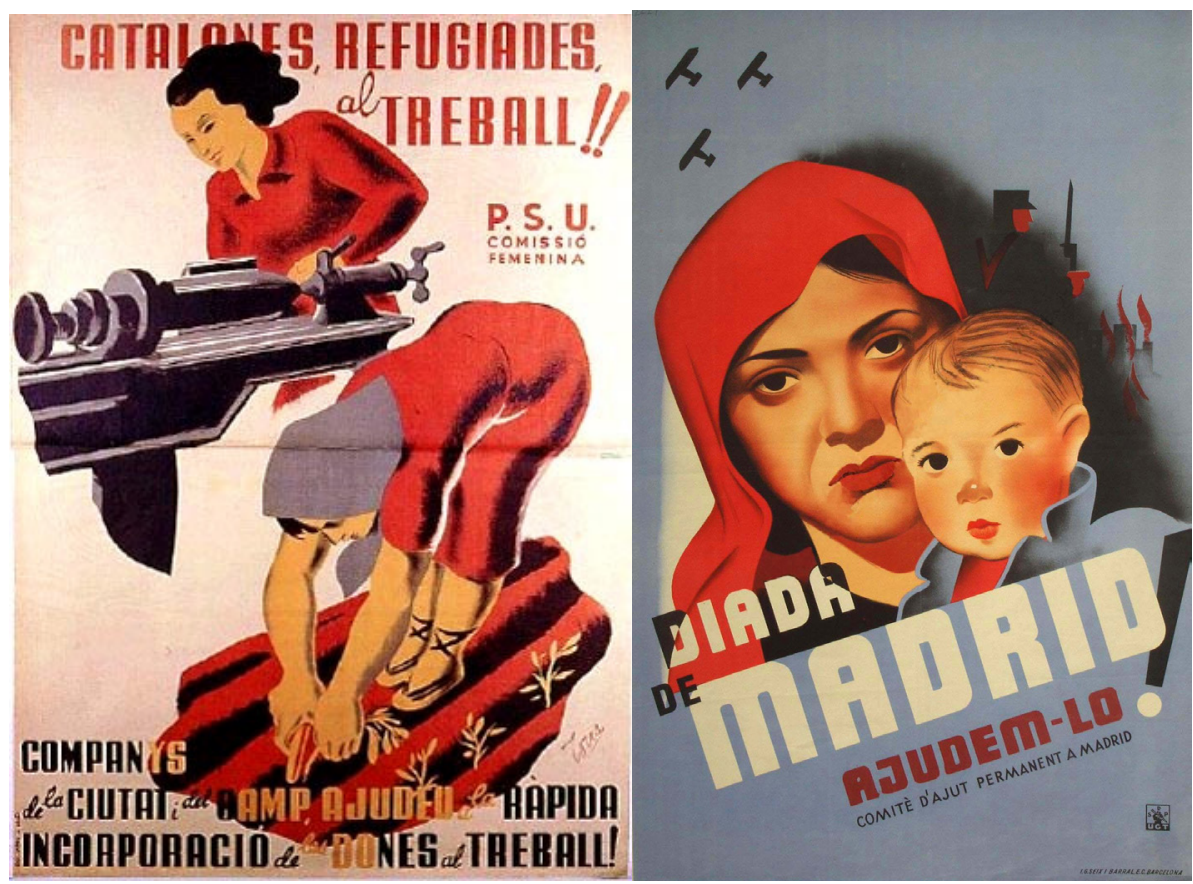

Fuente: Carteles del Archivo General de la Guerra Civil (2005)

La 'mujer-trampa' es el último arquetipo; menor cuantitativamente que los anteriores, connotado negativamente y focalizado en dos temáticas: la que alerta a los combatientes del peligro que representa la mujer como transmisora de enfermedades venéreas (imagen 6) y la que la acusa de derrotista o quintacolumnista. 
Imagen 6: Cartel editado por el Cuerpo de Seguridad, Sanidad, Lucha Antivenérea (1938).

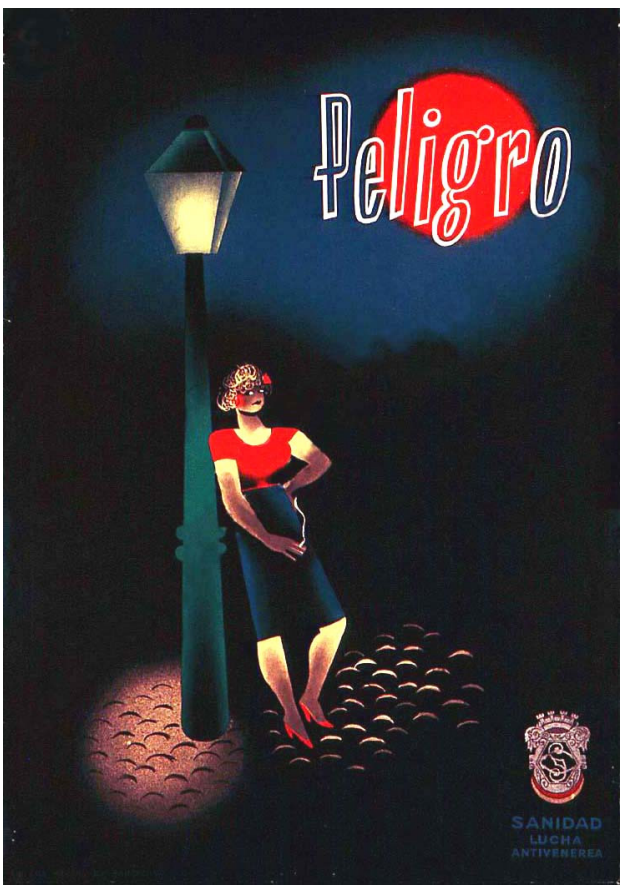

Fuente: Carteles del Archivo General de la Guerra Civil (2005)

El discurso visual sobre los tres arquetipos se sitúa por completo en el espacio público. Frentes, calles, comedores populares, refugios u hospitales son algunos de los escenarios donde transcurren las acciones. Como pone de manifiesto Gómez-Ferrer (2007: 32), "la guerra civil produce una nueva situación que rompe la estricta división entre lo privado y lo público, y favorece la transgresión de espacios, normas, costumbres, actitudes e indumentaria por parte de las mujeres."

La 'mujer-heroína' trabaja, cose, atiende enfermos, refugiados o niños; también es capaz de desfilar fusil al hombro, hacer guardia, luchar. Acciones todas que expresan compromiso con el esfuerzo bélico en la retaguardia y en los frentes. Conviene señalar, sin embargo, que los carteles referidos al último conjunto de acciones, más que un reflejo de la participación real de la mujer en el campo de batalla fueron un acicate para que los hombres emulasen su ejemplo y acudiesen a los frentes, especialmente a partir de octubre de 1936, cuando el gobierno instó a la mujer a abandonar las armas y colaborar desde la retaguardia, donde "se convirtió en trabajadora, ama de casa, madre, educadora, sanitaria... teniendo, también que realizar labores de aprovisionamiento (...)" (Domingo, 2004: 192).

El perfil de las figuras que acompañan a la mujer en las composiciones refuerza la idea, tanto de su compromiso como de su creciente presencia en espacios de la esfera 
pública. El conjunto más representado ( $43 \%$ de los carteles, frente al $19 \%$ en la etapa anterior) es el de la mujer acompañada por uno o más hombres, en su mayoría soldados, bien porque ella sea una combatiente más o una enfermera en la retaguardia. En este último caso también aparece en compañía de otras figuras, como los niños. La maternidad se politizó hasta el punto de que, como explica Nash (2011: 60) "la típica madre y proveedora de servicios colectivos, tejiendo jerséis para los soldados, curando enfermos y atendiendo a refugiados, simbolizó un nuevo valor social de las mujeres".

Como se ha señalado, la 'mujer-heroína' no suele representarse de manera aislada, acostumbra a formar parte de grupos más amplios, lo que enfatiza su compromiso y la apropiación de nuevos ámbitos de actividad. Esta tendencia narrativa no supone la desaparición de representaciones individualizadas, usuales en el periodo 193136 , sino que se ocupa, por primera vez, de figuras públicas. La notoriedad en su lucha contra el fascismo las ha transformado en ejemplos, como en el caso del cartel dedicado a Dolores Ibárruri, una de las nueve mujeres que fueron diputadas durante la República, o en el de Lina Odena, la joven obrera catalana, caída en el frente de Granada a las pocas semanas de comenzar la guerra.

También la indumentaria es un atributo de la 'mujer-heroína'. La distribución de frecuencias revela una elevada presencia de la categoría 'uniformes', que incluye toda aquella vestimenta identificativa de una actividad: enfermeras, trabajadoras fabriles, camareras o maestras, e incluye también el más emblemático de la época, el mono de miliciana, transformado no solo en símbolo de la Revolución, sino de la emancipación femenina, al equiparar estéticamente a hombres y mujeres y unirlos en pos de un objetivo común: la victoria (Domingo, 2004: 189).

La 'mujer-víctima' huye, llora o abraza y protege a una criatura. El escenario de su dolor e indefensión, cuando es reconocible, es siempre público. Las composiciones que caracterizan a este arquetipo describen estructuras familiares que pivotan sobre el binomio mujer-niño y que, en ocasiones, se amplían para incluir ancianas y ancianos. La ausencia del hombre es un denominador común, reflejo impuesto por la dinámica del conflicto, que intensifica la vulnerabilidad de la figura femenina. Otro rasgo distintivo de la 'mujer-víctima' tiene que ver con su indumentaria. La distribución de frecuencias de este elemento indica que el pañuelo de cabeza aparece en 19 composiciones, y en 12 identifica a la mujer refugiada. Refuerza la idea anterior el hecho de que sólo en una cuarta parte de los 16 carteles que hablan de 'ayuda y solidaridad' hacia mujeres, la figura femenina no lleve esa prenda.

La 'mujer-trampa' es la que socava la fortaleza del frente a través de la transmisión de enfermedades venéreas, y mina la cohesión de la retaguardia mediante el derrotismo y el espionaje. Los carteles que muestran este arquetipo alertan de los peligros que comporta, y por esa razón connotan negativamente las acciones que realiza la mujer: fumar, insinuarse, hablar o escuchar con atención. De los 9 carteles que muestran este arquetipo, 6 advierten de los riesgos que suponen para los soldados la prostitución o la promiscuidad. En la mayoría de estos diseños sólo aparecen las figuras 
de un hombre y una mujer. La desnudez, que en la etapa previa se había reservado para representaciones simbólicas y estaba cargada de pureza, durante la guerra pasa a identificar una mujer real que amenaza la salud de los combatientes.

\section{Conclusiones}

En Cataluña, como en el resto de España, el cartel fue durante el periodo 1931-39 una herramienta de comunicación y movilización políticas esencial. La presencia de la figura femenina como elemento compositivo no constituyó una novedad en los diseños de esta etapa, lo fue la gama de usos que su representación adoptó y, especialmente, los cambios profundos que experimentó a raíz del estallido de la guerra.

Los dos periodos estudiados son coincidentes en el tratamiento que la propaganda dio a la imagen de niñas. Se limitó a ser un recurso gráfico para referirse a la infancia. En cambio, el tratamiento de la figura femenina adulta fue más rico y permite distinguir dos usos. El que corresponde a una representación simbólica de alguna entidad (territorial o política), y el que describe una 'mujer real', entendida como sujeto integrado en un contexto histórico, cuyos atributos de género son indesligables del ejercicio de ciertas actividades o roles sociales.

La producción cartelística fue más prolífica a la hora de representar la mujer real. Entre 1931-36 el discurso visual muestra un equilibrio entre dos imágenes de figura femenina: una tradicional, ubicada en el espacio doméstico, y otra, renovadora, correlato de la legalidad republicana y situada en los espacios sociales que el nuevo régimen le ofrece.

Durante la guerra la propaganda deshace ese equilibrio y desdibuja los límites entre el espacio privado y público. Por un lado, la representación del ámbito doméstico muestra los hogares como focos de colaboración activa con el frente, mientras que el énfasis en el dolor y el desarraigo de la mujer refugiada se narran a través de la negación del espacio privado. Temas y acciones configuran tres arquetipos bien distintos: la mujer-víctima, la mujer-trampa y el más recurrente, la mujer-heroína, comprometida con el esfuerzo bélico en el frente y en la retaguardia. Este arquetipo fue el escenario de un debate social $\mathrm{y}$, a la vez propagandístico, sobre la representación de la figura femenina en tiempos de guerra. Debate entre la ruptura, simbolizado en la imagen de la miliciana, y la tradición, encarnada en el retorno a la iconografía de la madre solidaria. 


\section{Bibliografía}

AGUADO, A. (2011). "Modernes i ciutadanes: gènere i igualtat a la Segona República". En: GINARD, D. (coord.) (2011). Dona, Guerra Civil i franquisme. Palma: Documenta Balear. p. 16-43.

(2008). "Identidades de género y culturas políticas en la Segunda República". En: Pasado y Memoria. Revista de Historia Contemporánea, $\mathrm{n}^{\circ} 7$. Universidad de Alicante. p. 123-141.

ARXIU NACIONAL DE CATALUNYA (2007). Cartells de la Guerra Civil a Catalunya. Barcelona: Generalitat de Catalunya.

BRANCIFORTE, L. (2009). "Legitimando la solidaridad femenina internacional: el Socorro Rojo". En: Arenal, n 1, vol. 16. Universidad de Granada. p. 27-52.

CARULLA, J. (2007). La Guerra Civil en 2000 carteles. Barcelona: Postermil.

Carteles del Archivo General de la Guerra Civil [Recurso electrónico]. (2005). Madrid: Ministerio de Educación, Cultura y Deporte.

Cartells catalans. La República en guerra, 1936-1939 (2009). Barcelona: Enciclopèdia Catalana.

Cartells de la Col·lecció Fornas: producció gràfica de la Segona República i la Guerra Civil. (2006). Barcelona: Parlament de Catalunya.

DOMINGO, C. (2004). Con voz y voto: las mujeres y la política en España 19311945. Barcelona: Lumen.

FUNDACIÓN PABLO IGLESIAS (2008). Carteles de la guerra. Madrid: Fundación Pablo Iglesias.

GÓMEZ ESCARDA, M. (2008): "La mujer en la propaganda política republicana de la guerra civil española". En: Barataria, no 9, Toledo: ACMS. p. 83-101.

GÓMEZ-FERRER, G. (2007). "República y Guerra Civil: una perspectiva de género". En: República i republicanisme, vol. 2. Barcelona: UAB, p. 1-62. http:// bit.ly/1aEWLDS. [16-07-2013]

JULIÁN, I. (1994). "Dona i Guerra Civil a Espanya (1936-1938): representació gràfica". En: Pensar las diferencias. Barcelona: Institut Català de la Dona; Universitat de Barcelona. p. 137-148.

NASH, M. (2011). "Ciutadanes en guerra: les dones republicanes en la lluita antifeixista”. En: GINARD, D. (coord.) (2011). Dona, Guerra Civil i franquisme. Palma: Documenta Balear. p. 45-66.

TENA, D. (2005). Diseño gráfico y comunicación. Madrid: Pearson-Prentice Hall.

VILANOVA, M. (1999). "Participació electoral i vot femení a Catalunya". En: RIQUER, B. (dir.) Història, política, societat i cultural dels Països Catalans. Vol. 12. Barcelona: Enciclopèdia Catalana. p. 108-109.

(1986).Atlas electoral de Catalunya durant la Segona República. Barcelona: Fundació Jaume Bofill, La Magrana. 


\section{Los autores}

Alfonso González Quesada, doctor en Ciencias de la Información, licenciado en Filología Catalana y diplomado en Biblioteconomía y Documentación. Profesor titular del Área de Documentación de la Universitat Autònoma de Barcelona. Miembro del GRP (Grup de Recerca en Publicitat). Autor de diversos trabajos sobre gráfica mural, de entre los que destaca iVaya, valla! Gráfica revolucionaria cubana. Co-comisario de la exposición homónima.

Patrícia Lázaro Pernias, doctora en Ciencias de la Información. Profesora Titular del Dep. Publicidad, Relaciones Públicas y Comunicación Audiovisual de la Universitat Autònoma de Barcelona. Miembro del GRP. Ha publicado diversos trabajos relacionados con los lenguajes audiovisuales, el género y la creatividad. Uno de los más recientes es "Is there gender bias in the assessment of advertising creativity?", del que ha sido coautora. 